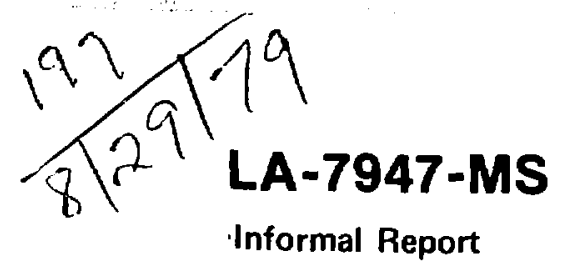

Near-Term and Late Biological Effects of Acute and Low-Dose-Rate Continuous Gamma-Ray Exposure in Dogs and Monkeys 


\title{
Near-Term and Late Biological Effects of Acute and Low-Dose-Rate Continuous Gamma-Ray Exposure in Dogs and Monkeys
}

\author{
J. F. Spalding
}

L. M. Holland

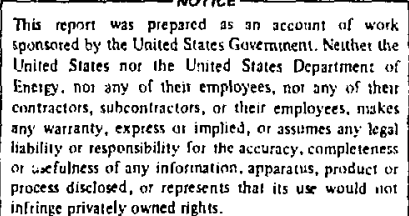


NEAR-T'ERM ANO I.ATE BIOLOGICAL. EFFECTS OF ACUTE ANI LOW-DOSE-RATE

CON'INLIOUS CAMMA-RAY EXPOSURE IN DOGS ANI) MUNKEYS

by

J. F. Spalding and 1.. M. Holland

\begin{abstract}
ABSTKACT
Monkeys (Macaca mulatla) ard dogs (bragle) were given thirteen lo0-rad gammaray doses at 28-day intervils. The comparative response (injury and recovery) of the hematopoictic system of the two species was observed at 7 -day intervals during the exposure regine. At 84 days after the thirteenth gamna-ray dose, the 1300-rad conditioned and control dogs and monkeys were challenged continuously with gamma rays at $35 \mathrm{R} /$ day until death to deternine the amount of radiation-induced injury renaining in condicioned animals as a reduction in mein survival time. Dogs (50\%) and monkeys (8\%) died from injury iscurred during conditioning exposures. Thus, the comparative response (in lerms of lethality) of degs and monkeys to dose protraction by acute dose fractionation was similar to what we would expect from a single acute dose.

The mean survival limes for nonconditiond dogs and monkeys during continuous exposure at $35 \mathrm{k} /$ day were the same $(-1400 \mathrm{~h})$. Thus, the hematopoietic response of the two speries by this method of duse protraction was not significantly different. Mean survival times of conditioned dogs and monkeys during the continuous 35-R/day gamma-ray challenge exposure were greater (sjgnificant in dogs but not in monkeys) than for their control counterparts. Thus, Jong-tern radiation-induced injury was not measurabir by this method. Condjtioning doses of more than 4 times the acute $\mathrm{LO}_{5}^{30}$ in dogs and approximately 2 times that in monkeys served only to increase. both mean survival Lime and varjance in a ganma-ray stress environment wilh a dose rate of $35 \mathrm{k} / \mathrm{day}$.
\end{abstract}

\section{INTRODUCTION}

The near-term and late biological effects on the human exposed to ionizing radiations under various dose and dose-rate conditions are predicated on experience with human accidents and experimental data obtained on other animal species. Human accident data involving exposure to ionizing radiations are questionable because the exposure factors are not well-defined. The response to radiation exposure differs widely among experimental mammalian species, and these differences are not necessarily consistent within a wide range of dose rates. 1

The lethal dose, $\mathrm{LD}_{50}^{30}$, from acute (high-doserate) whole-body exposure to $x$ or gamma rays in man is not known, but we estimate it to be between 400 and $500 \mathrm{rad}$. This would be intermediate to the acute $\mathrm{LD}_{50}^{30}$ of the monkey (Macaca mulatta) of approximately $600 \mathrm{rad}^{2-5}$ and of the dog (beagle) of approximately 300 rad. ${ }^{6-8}$ The ameliorating effects of dose protraction by either the fractionation or continuous low-dose-rate exposure method have been documented for the $\operatorname{dog}^{9-12}$ but are not as well known for subhuman primates. ${ }^{10-14}$ If man's biological response to acute exposure is intermediate to that of the dog and monkey, it is probably intermediate to, or at least within, the response range of these two species over a wide spectrum of dose rates. Thus, comparative studies with dogs and monkeys of exposure effects at sublethal dose rates are needed. This investigation was performed to obtain data required for reasonable predictions concerning dose-rate effects in man. 


\section{II . METHODS}

This investigation was performed to obtain data on comparative effects between and within two species: the monkey and the dog. Data were compiled for near- and long-term radiation injury induced during dose protraction, by acute fractionation, and by continuous low-dose-rate exposure. Twenty-four animals, 12 male dogs and 12 male monkeys, were subjected to a conditioning, regime consisting of thirteen separate 100 -rad gamma-ray exposures spaced at 28 -day intervals. Periods of 28 days between exposures were used because this time span is a reasonable estimate of the recovery half time for $x$-ray or gamma-ray injury in the dog, monkey, and man. These acute conditioning doses were given at a dose rate of approximately $16 \mathrm{R} / \mathrm{h}$. Eighty-four days after the thirteenth 100-rad exposure, these conditioned animals and 12 nonconditioned animals of each species ( 8 male and 4 female dogs and 12 male monkeys) were placed in a continuous gamma-ray environment at a dose rate of $35 \mathrm{R} /$ day for terminal challenge exposures. The continuous challenge exposures were used to compare the response of the dog and monkey to dose protraction and to determine residual injury in conditioned animals expressed as a reduction in mean survival time.

The dose rate for challenge exposures ( $35 \mathrm{R} /$ day) was selected so that the response of nonconditioned dogs could be compared with dog studies done at the Argonne National laboratory at the same dose rate 9 and also with our own conclitioned dogs and mankeys and nonconditioned monkeys. Aluminum alloy squeezetype cages $813 \mathrm{~mm}$ in width, $813 \mathrm{~mm}$ in depth, and $1067 \mathrm{~mm}$ in height were used for restraint of the monkeys, and glass/plastic squeeze-typc cages $813 \mathrm{~mm}$ in width, 71] $\mathrm{mm}$ in depth, and $924 \mathrm{~mm}$ in height were used to restrain the dogs during conditioning and challenge exposures. The animals were restrained to one-half the cage depth during the relatively short fractionated conditioning doses and were given the comfart provided by maximum cage dimensions during the continuous challenge exposure. The restraint cages were positioned at $4.56 \mathrm{~m}$ for conditioning fractions and at $4.86 \mathrm{~m}$ for challenge exposures. Bose rates were measured in air at the center of the restraining cage with $0.25-, 1.0-$, and $2.5-R$ highenergy Victoreen chambers. The dose measurements were corrected for pressure and temperature and converced to tissue dose in rad by the conversion factor $1 \mathrm{R}=0.96 \mathrm{rad}$. The comparative response to hematopoietic tissue of dogs and monkeys to dose protraction by fractionation and continuous lowdose-rate exposure was observed from blood samples obtained by venipuncture. Blood volumes ( $2 \mathrm{ml}$ or less) were taken prior to and at 7-day intervals during and/or following gamma-ray exposure.

\section{RESULTS AND DISCUSSION}

The ameliorating effects of dose protraction by the fractionation method used in this investigation were less obvious in dogs than in monkeys. Six of 12 dogs started on the fractionation exposure regime succumbed to radiation injury from the eighth through the thirteenth 100-rad exposure. One monkey died 18 days after the eighth 100-rad gamma-ray exposure.

Packed cell volumes (PCVs) and leucocyte counts observed in monkeys and dogs 27 days after each of the thirteen acutely delivered conditioning exposures are shown in Figs. 1 and 2. Dog and monkey PCVs remained at about the pre-exposure level through the seventh exposure (Fig. 1). Following the seventh exposure, dog PCVs declined

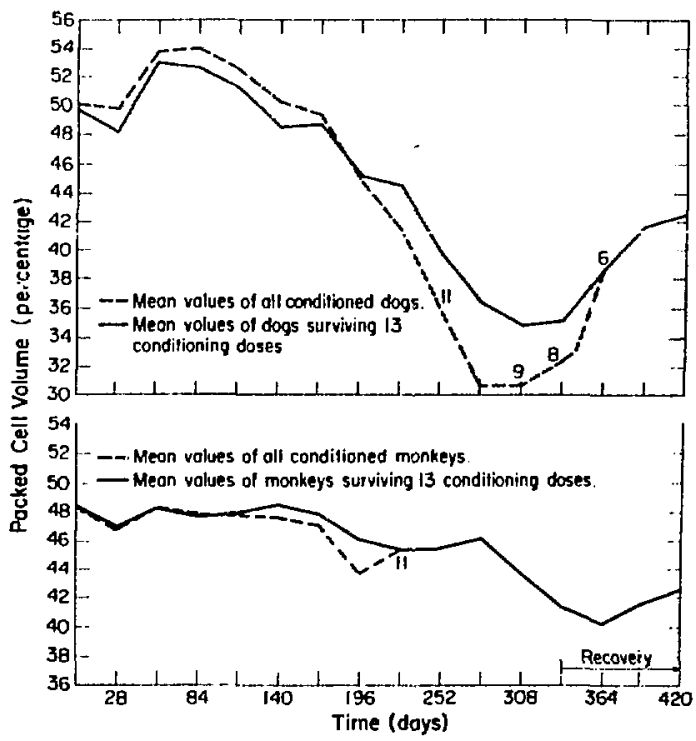

Fig. 1. Mean packed cell volume (PCV) of dogs and monkeys 27 days after each of thirteen acute 100-rad gampra-ray exposures and during 84 days of recovery. The numbers indicate the animals included in the means; 12 were started. 


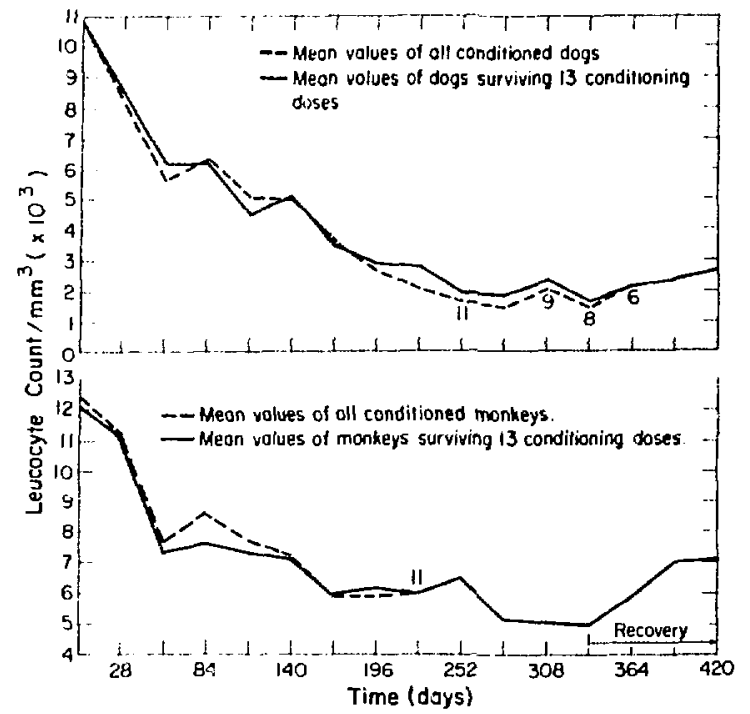

Fig. 2. White blood cell (WBC) counts of dogs and monkeys 27 days after each of thirteen acute 100-rad gamma-ray exposures and during 84 days of recovery. The numbers indicate the antimals included in the means; 12 were started.

steadily to $60-70 \%$ of the pre-exposure value after accumulating $L 100$ rad (Fig, 1). Recovery following conditioning doses in dogs was at about the same rate as the decline, and PCVs reached $\sim 85 \%$ of the pre-exposure value 84 days after the thirteenth 100-rad dose. One of the 6 dogs surviving the conditioning exposure kept the PCV mean of the group down with a value of 13 . In general, inter-animal hematological observations were very similar. The PCVs of monkeys remained within about $95 \%$ of the pre-exposure value through the eleventh 100-rad dose, then dropped to a low of approximately $85 \%$ of the base-line level. Eighty-four days after the thirteenth gamma-ray exposure, monkey PCVs had returned to about $90 \%$ of the pre-exposure values.

White blood cell (WBC) numbers in dogs dropped to about $18 \%$ of pre-exposure values during the fractionation regime. At the end of the 84-day period allowed for recovery, leucocyte numbers returned to only $24 \%$ of pre-exposure values (Fig. 2). The initial WBC decrease in monkeys was comparable to dogs but leveled off at about $40 \%$ of the pre-exposure value and returned to $-60 \%$ of the base-line value during the 84 -day recovery period (Fig. 2).
Differential leucocyte counts were done to observe the comparative response of neutrophils, lymphocytes, and eosinophils from dogs and monkeys exposed under these same conditions. Neutrophil, lymphocyte, and eosinophil values for dogs and monkeys are plotted in Figs. 3-5. The neutrophilto-lymphocyte $(N / L)$ ratio increased from the preexposure value of -2.0 to -2.75 furing the first five acute exposures. This $N / L$ increase was followed by a similar decrease, approaching 1.0 during the sixth through the tenth acute exposure. The $N / L$ ratio returned to $\sim 1.4$ (somewhat less than the base-line ratio of -2.0 ) during the 84 -day recovery period (Figs. 3 and 4 ).

The N/L response of monkeys was similar to that of dogs following the first two exposures but returned to the base-line value $(-1.0)$ after the third exposure. Unlike dogs, the $\mathrm{N} / \mathrm{L}$ ratio of monkeys was generally less than 1.0 during the last ten acute gamma-ray exposures and somewhat higher than the base-1ine value after the 84 -day recovery period (Figs. 3 and 4 ).

The eosinophil response of the two species to acute gamma-ray fractionation was quite different. The dog, being more radiosensitive to acute doses of ionizing radiation, showed a steady decrease in

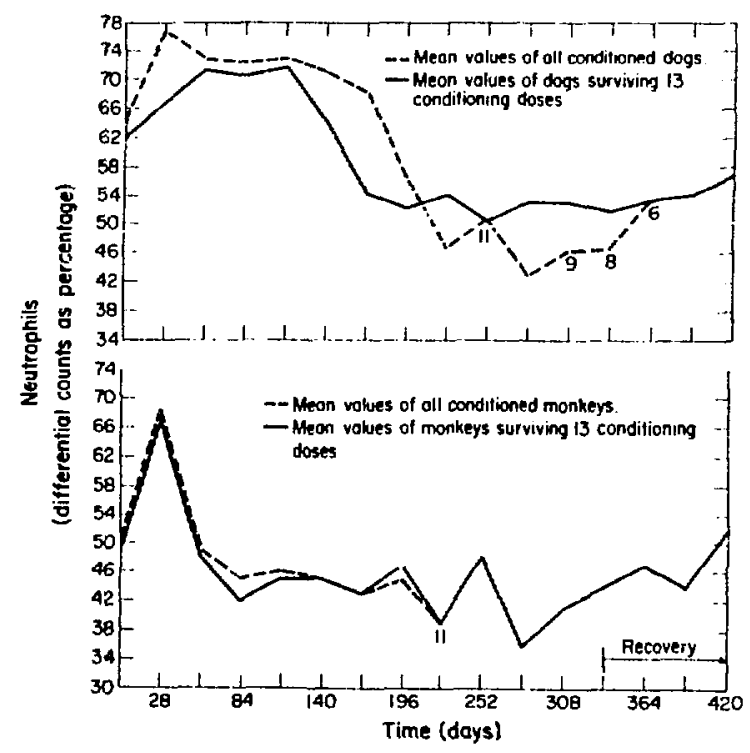

Fig. 3. Neutrophils of dogs and monkeys 27 days after each of thirteen acute 100-rad gamma-ray exposures and during 84 days of recovery. The numbers indicate the animals included in the means. 


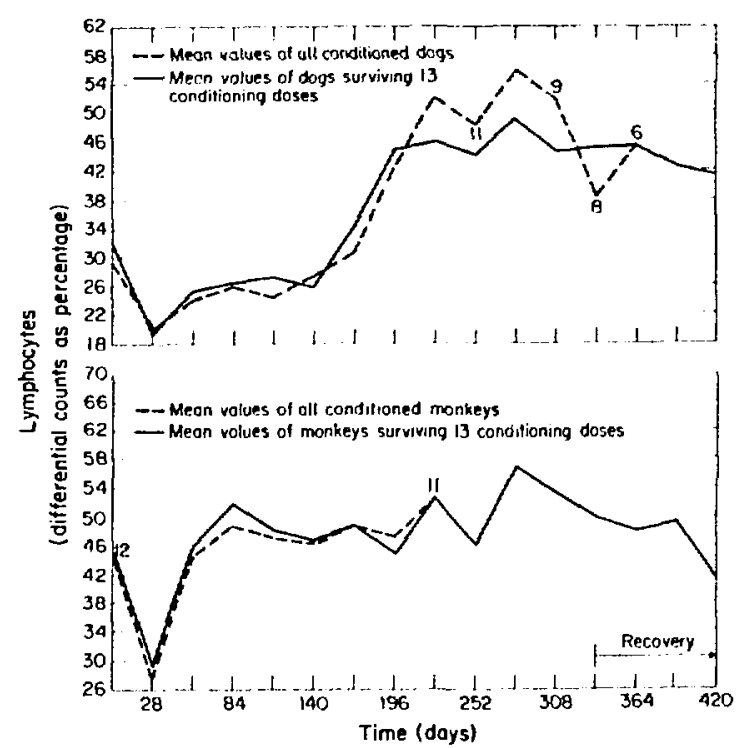

Fig. 4. Lymphocytes of dogs and monkeys 27 days after each of thirteen acute 100-rad gamma-ray exposures and during 84 days of recovery. The numbers indicate the animals included in the means.

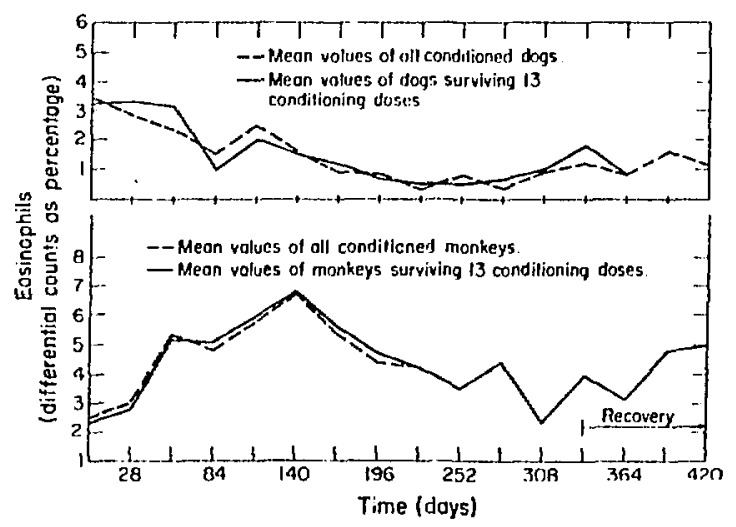

Fig. 5. Eosinophils of dogs and monkeys 27 days after each of thirteen acute 100-rad gamma-i u exposures and during 84 days of recovery.

eosinophils (ta zero in some animals) after the ninth exposure. Following 84 days of recovery, the number of eosinophils remained below the base-line number by $-33 \%$ (Fig. 5). In contrast, eosinophil counts in monkeys, the more radioresistant of the two species to acute $x$ - and gamma-ray exposure, increased steadily during the first six acute gamna-ray exposures to $\sim 280 \%$ above the base-1ine number. Although the number declined from the sixth through the thirteenth exposure, it remained above the pre-exposure level throughout the exposure series and was a factor of 2.0 above the base-line value 84 days after the thirteenth acute dose (Fig. 5).

An observation of at least academic interest

is shown in Fig. 6. An early concept of radiation injury and recovery proposed by Blair 15,16 and used by the National Committee on Radiation Protection and Measurements 17 to estimate the effects of exposure to radiation in an emergency suggested that radiation injury can be relegated to two components: reparable and irreparable. In man, the recovery half time $\left(\mathrm{RT}_{5 ;}\right)$ of the reparable component was set at approximately 28 days, and approximately $10 \%$ of any whole-body exposure was presumed to induce an undefined irreparable lesion that would ultimately he seen as a dose-dependent reduction in normal life span. Earlier work with mice showed this concept to be useful in predicting the consequences of gamma-ray exposure within a limited range of exposure conditions if animal subjects are not prone to some dose- and/or doserate-dependent neoplasia. 18

When the two-component concept and the factors $\mathrm{RT}_{50}=28$ days and irreparable lesion $=10 \%$ of the exposure dose are applied to the fractionation exposure regime used to provide conditioning doses to dogs and monkeys in this study, the theoretical equivalent residual gamma-ray dose builds up as shown in Fig. 6. The residual dose from 1300 rad delivered in thirteen acute fractions peaked at slightly over 300 rad. This dose is approximately

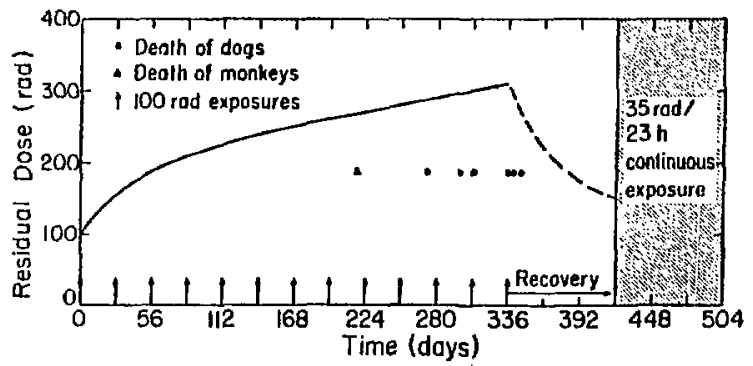

Fig. 6. Theoretical equivalent residual dose from thirteen 100-rad exposures separated by 28-day periods of recovery. One monkey and 6 dogs died from radiation injury at the times indicated. 
one-half of the $\mathrm{CD}_{50}^{30}$ of the monkey, ${ }^{2-4}$ and only 1 of $12(8 \%)$ monkeys died from gamma-ray injury. The $L D_{50}^{30}$ of the dog $(300 \mathrm{rad})^{6-8}$ was reached by the equivalent residual dose of 1300 rad delivered in thirteen equally spaced acute doses, and 6 of 12 $(50 \%)$ dogs succumbed to the radiation injury. Without exception, $\operatorname{dog}$ and monkey deaths were the result of failure of the hematopoietic system. Under this same radiation exposure regime, we would p redict approximately $25 \%$ lethality in man with survivors exhibiting few, if any, acute syndrome effects.

Response of the hematop ic system of conditioned and nonconditioned doga and monkeys to dose protraction by low-dose-rate continuous gamma-ray exposure ( $35 \mathrm{R} /$ day) is shown in Figs. 7-11. Nonconditioned dogs and monkeys showed similar response patterns for PCVs and WBCs during continuous terminal exposures (Figs. 7-9). Dog PCVs were slightly higher than monkey PCVs prior to exposure and started to drop sooner. However, from the twenty-first day on after exposure, $P C V$ response in both species was very similar (Fig. 7). Preexposure leucocyte levels were about $60 \%$ higher in the monkeys than in the dogs; however, the WBC loss pattern was quite steep from the onset of exposure in both species and followed the same pattern during the course of terminal exposure (Figs. 8 and 9).

Base-line $N / L$ ratios in nonconditioned dogs and monkeys were -2.7 and 1.8 , respectively (see Figs. 8-10). These ratios remained about the same during the first 21 days of exposure in both dogs (Figs. 8 and 10) and monkeys (Figs. 9 and 10). Following 21 days of exposure, dog N/L ratios gradually decreased to $\sim 1.0$ at 49 days and were less than 1.0 from the sixtieth day (Figs. 8 and 10). Monkey $N / L$ ratios declined more sharply than dogs and were less than 1.0 from the twenty-eighth day of exposure (Figs. 9 and 10). The majority of deaths occurred after the $N / L$ ratio was less than 1.0 in both species.

Eosinophils in nonconditioned dogs and monkeys exposed continuously at $35 \mathrm{R} /$ day showed similar responses (Fig. 11). This was in contrast to the eosinophil response of the two species to dose protraction by the acute fractionation method (Fig. 5). In this study, eosinophil response early in the two exposure regimes used seemed to be

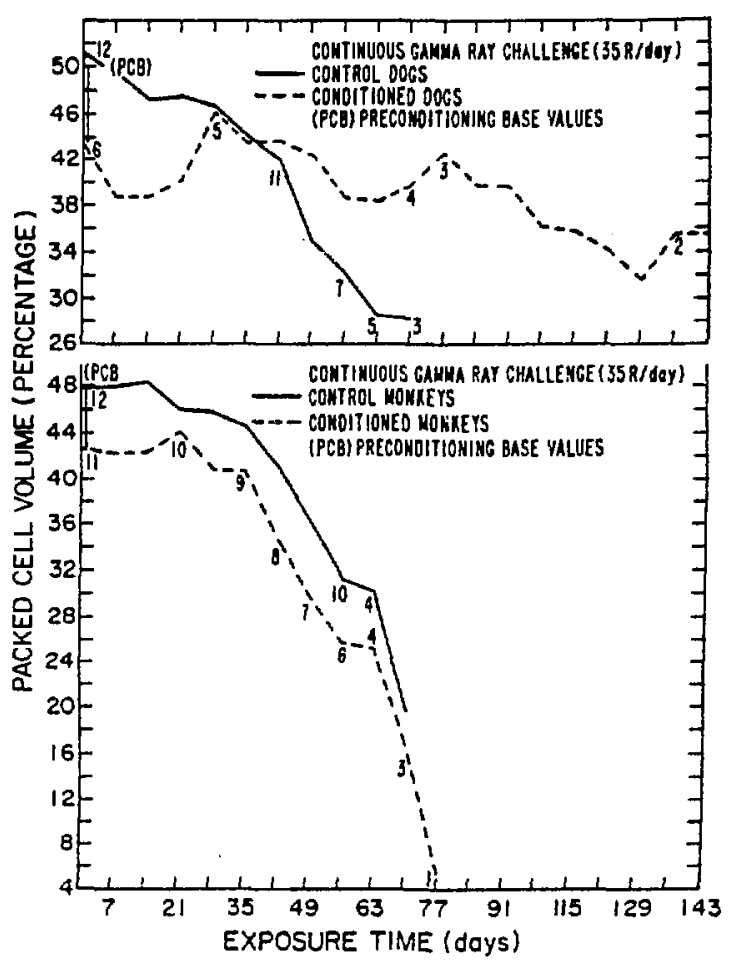

Fig. 7. Packed cell volume (PCV) of gamma-ray conditioned (1300 rad) and nonconditioned dogs and monkeys during a continuous $35-R /$ day gamma-ray stress. The numbers indicate the animals in the mean values.
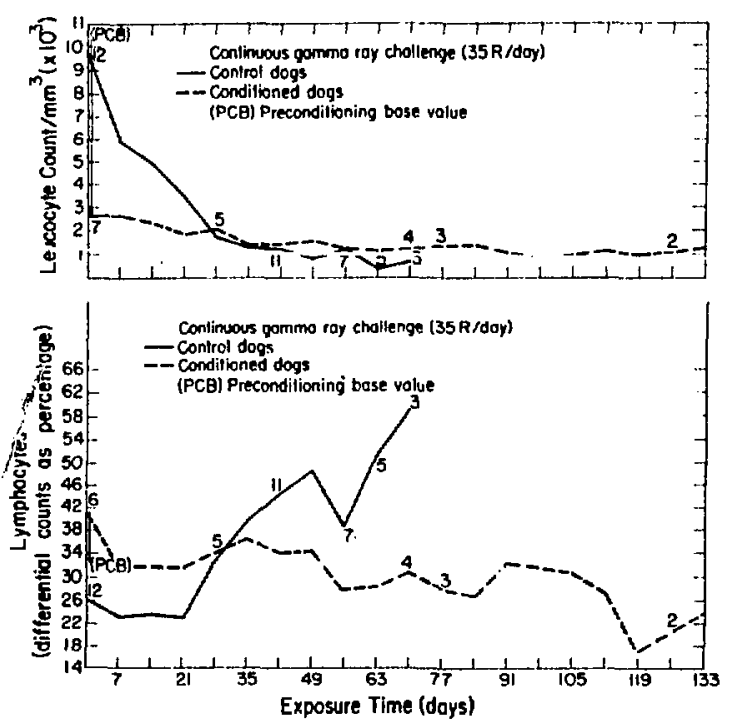

Fig. 8. Leucocytes and lymphocytes of gavma-ray conditioned (1300 rad) and nonconditioned Jogs during a continuous 35-R/day gammaray stress. The numbers indicate the animals in the mean values. 

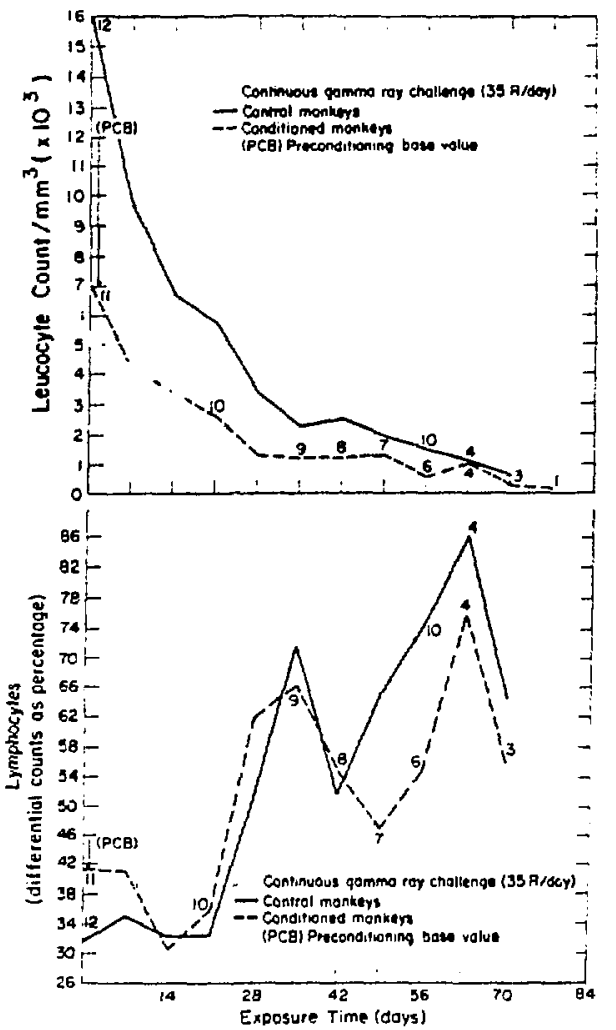

Fig. 9. Leucocytes and lymphocytes of gamma-ray conditioned ( $1300 \mathrm{rad}$ ) and nonconditioned monkeys during a continuous 35-R/day gammaray stress. The numbers indicate the animals in the mean values.

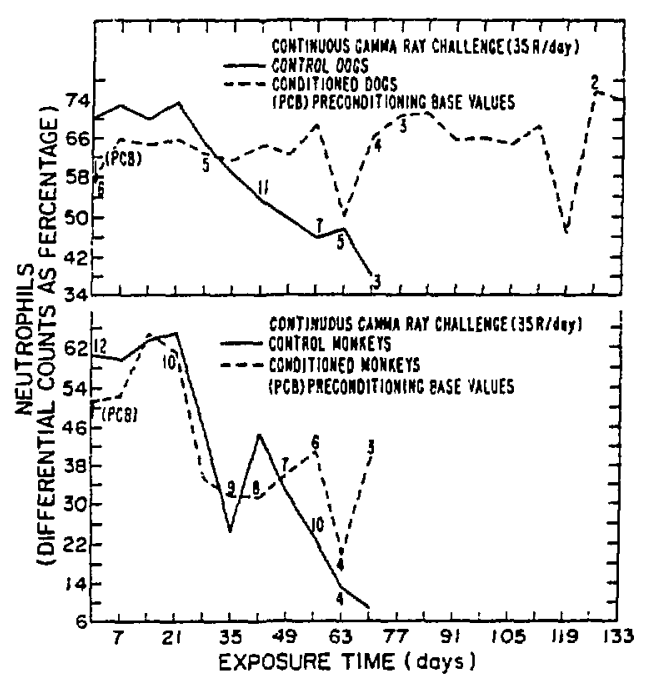

Fig. 10. Neutrophils of gamma-ray conditioned (1300 rad) and nonconditioned dogs and monkeys during a continuous 35-R/day gamma-ray stress. The numbers indicate the animals in the mean values.

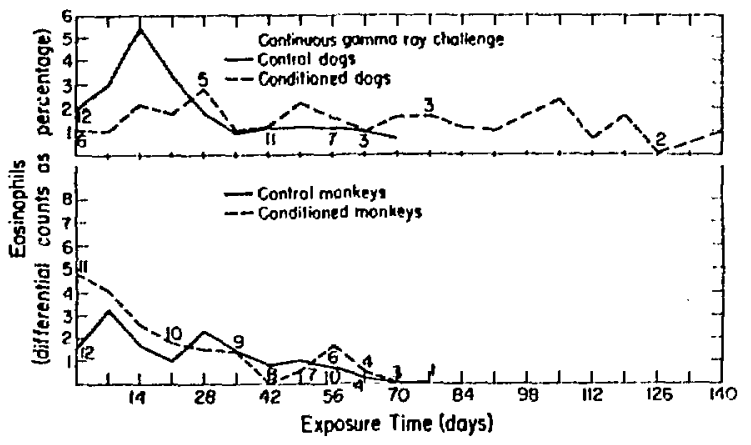

Fig. 11. Eosinophils of gamma-ray conditioned (1300 rad) and nonconditioned logs and monkeys during a continuous 35-R/day gamma-ray stress. The numbers indicate the animals in the mean values.

associated with the radioresistance of the two species. The general trend of the differential eosinophil count was up following the first five acute exposures in the monkey (the species most resistant to acutely delivered radiation), while that of the dog (comparatively sensitive to acutely delivered radiation) was generally down (Fig. 5). When the dose was delivered continuously at a dose rate that produced similar responses in dogs and monkeys, the differential eosinophil count followed a similar pattern in both species (Fig. 11). As stated earlier, the $\operatorname{dog}$ is a factor of - 2.0 more radiosensitive to single acute doses of ionizing radiation in the $L D_{50}^{30}$ range than the Macaca mulatta monkey. Our investigation shows that this difference in sensitivity persists when the dose is protracted by the acute fractionation method but does not hold when the continuous low-dose-rate method of dose protraction is used.

We have shown in earlier studies ${ }^{19}$ that dose protraction by fractionation with relatively lowlose-rate fractions $(4 \mathrm{R} / \mathrm{h})$ is more biologically damaging than dose protraction by continuous lowdose-rate exposures totaling the same dose over the same time period. Thus, as seen here, the comparative response among different species to a specific set of exposure conditions may not be predictive over a wide range of conditions. A species cannot be categorized as "radiosensitive" or "radioresistant" without exposure-condition qualifications. The results of this and earlier studies ${ }^{11-14}$ suggest that dose protraction by 
low-dose-rate cont inuous exposure brings the radiosensitivity of the bloud-forming tissue of the beagle and Macaca mulatta monkey (widely diffrient when acute exposures are used) to nearly the same response level of - $35 \mathrm{R} / \mathrm{day}$. With lower dose rates, there is evidence ${ }^{12}$ that the dog becomes more radioresistant than the monkey. Based on information from accidental exposures of human subjects, Atomic Bomb Casualty Commisision reports, and a report on an accidental low-dose-rate exposure in Mexico, ${ }^{20}$ we believe that the response of normal man to whole-body $x$ - or ganma-ray exposure would fall within the response Jimits of the dog and monkey over a wide range of dose-rote and total-dose conditions.

Mortality distributions and mean survival times of norconditioned dogs and monkeys exposed continuously to ganma rays at $35 \mathrm{R} / \mathrm{day}$ are shown in Fig. 12. Mean survival times and standard devialions for logs and monkeys were $1.387 \pm 258 \mathrm{~h}$ and $1445 \pm 207 \mathrm{~h}$, respectively. Neither morlality slopes nor mena survival times of nonconditioned dogs and monkeys differed significantly. This is in sharp contrast with the $~ 2.0-f o l d$ difference in acute $\left.{ }^{30}\right)_{50}^{30}$ of these mammalian species. The survival times of nonconditioned dogs at $35 \mathrm{R} /$ day are in good agreement with the work of Norris. ${ }^{9}$ Mortality distributions and mean survival times of dogs and monkeys conditioncd with 1300 rad of gamma rays and exposed continuously to gamma rays at $35 \mathrm{R} /$ day are shown in Fig. 13. Mean survival times and standard deviations were $3258 \pm 1535 \mathrm{~h}$ and $1942 \pm 644 \mathrm{~h}$ for dogs and monkeys, respectively. Mortality curve slopes and mear survival times for conditioned dogs and monkeys (Fig. 1.3) were significantly different, with dogs having a greater mean survival time than monkeys.

The attempt to measure late effects from radiation injury in dogs and monkeys as a reduction in mean sutvival time in a colltinuous gamma-ray stress environment ( $35 \mathrm{R} /$ day) was unsuccessful because the conditioned dogs and monkeys had significantly greater mean survival times than their control counterparts. Although the reduction in the meansurvival-time method has been used successfully with mice, ${ }^{21-23}$ an earlier attempt to measure residual injury in dogs and monkeys; conditioned with $660 \mathrm{rad}$ of gamma rays in a 10-day continuous ganma-ray

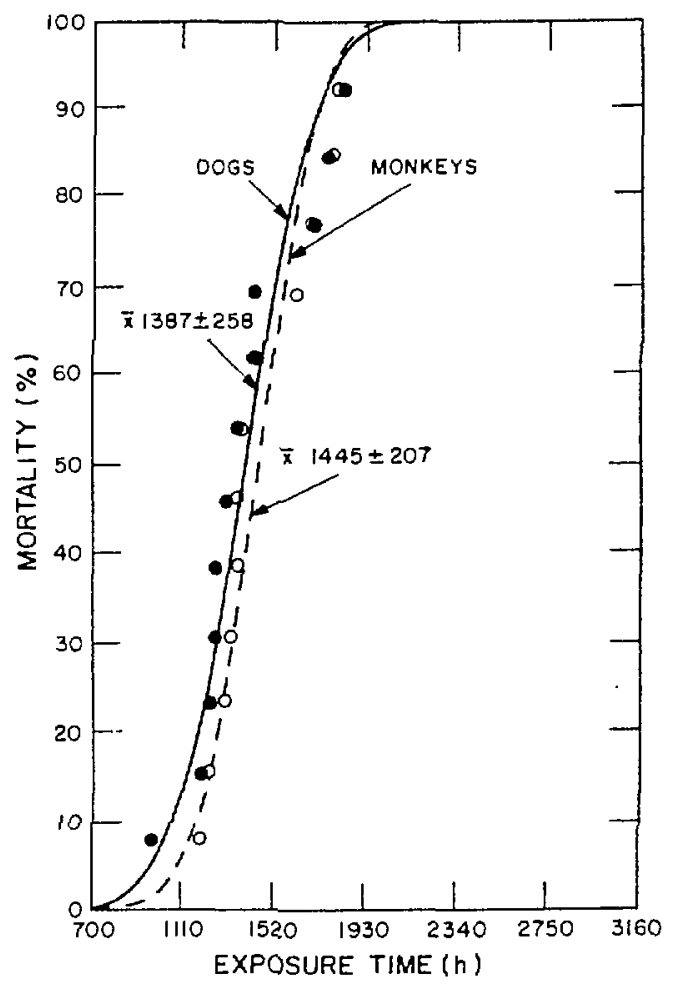

Fig. 12. Cumulative plot of mortality data and mean survival time (h) with standard deviation of nonconditioned dogs and monkeys exposed continuously to gamma rays at $35 \mathrm{R} / \mathrm{day}$.

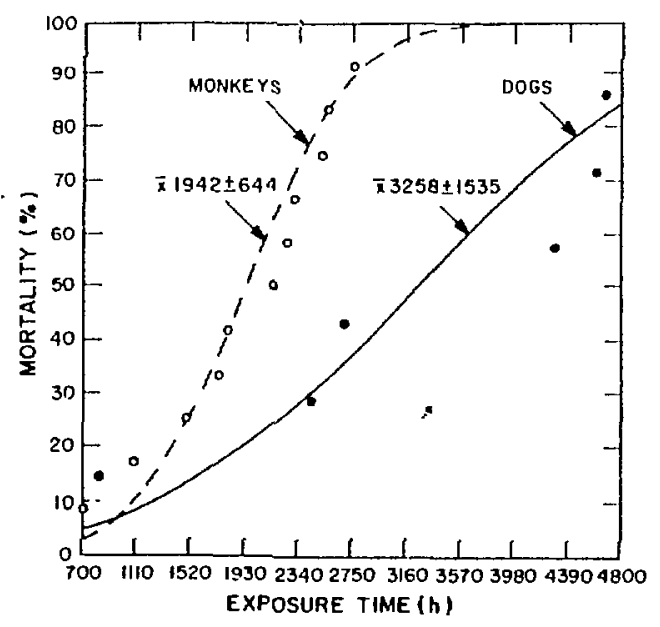

Eig. 13. Cumulative plot of mortality data and mean survival time (h) with standard deviation of gamma-ray conditioned (1300 rad) dogs and monkeys exposed continuously to gamma rays at $35 \mathrm{R} / \mathrm{day}$. 
exposure, with a gamma-ray stress challenge of $24 \mathrm{R} /$ day, was inconclusive, with the dog showing residual injury but not the monkey. 12

\section{ACKNOWLEDGMENTS}

The authors are grateful to P. M. Labauve, J. E. London, and E. A. Vigil for hematology and technical assistance, to $R$. F. Archuleta for design and fabrication of the exposure facility, to $0 . \mathrm{S}$. Johnson for dose and dose-rate calibrations, to J. R. Prine for pathology, and to G. L. Tietjen of the LASL Energy Systems and Statistics Group for statistician services and data analysis.

\section{REFERENCES}

I. N. P. Page, "The Effect of Dose-Protraction on Radiation Lethality of Large Animals," in Proceedings of a Symposium on Dose Rate in Mammalian Radiation Biology, D. G. Brows, R. G. Cragle, and T. R. Noonan, Eds. (UT-AEC Agricultural Research Laboratory and U. S. Atomic Energy Commission, Oak Ridge, Tennessee, July 12, 1968), report CONF-680410, pp. 12.112.23 .

2. E. Eldred and W. V. Trowbridge, "Radiation Sickness in the Monkey," Radiology 62, 65-73 (1957).

3. V. P. Bond and J. S. Robertson, "Vertebrate Radiobiology (Lethal Actions and Associated Effects)," Ann. Rev. Nucl. Sci. 7, 135-162 (1957).

4. U. K. Henschke and J. L. Morton, "Mortality of Rhesus Monkeys after Single Total Body Radiation," Amer. J. Roentgenol. 77, 899-909 (1957).

5. R. E. Stanley, L. J. Seigneur, and T. A. Strike, "The Acute Mortality Response of Monkeys (Macaca mulatta) to Mixed Gamma-Neutron Radiations and 250 KVP X Rays," Armed Forces Radiobiology Research Institute report AFRRI SP66-23 (1966).

6. C. A. Gleiser, "The Determination of the Lethal Dose $50 / 30$ of Total Body $X$-Irradiation for Dogs," Amer. J. Vet. Res. 14, 284-286 (1953).

7. J. N. Shively, S. M. Michaelson, and J. W. Howland, "The Response of Dogs to Bilateral Whole-Body Co 60 Irradiation. I. Lethal Dose Determinations," Radiat. Res. 9, 445-450 (1958)

8. V. P. Bond, T. M. Fliedner, and J. L. Archambéau, Eds., in Mammalian Radiation Lethality, A Disturbance in Cellular Kinetics (Academic Press, New York, 1965), Pp. 101-114.

9. W. P. Norris, in Radiation Toxicity in Dogs, Argonne National Laboratory report ANL-8070 (1973), pp. 29-34.
10. J. F. Spalding, L. M. Holland, and $0 . \mathrm{S}$. Johnson, "Kinetics of Injury and Repair in Monkeys and Dogs Exposed to Gamma-Ray Fractionation," Health Phys. 17, 11-17 (1969).

11. J. F. Spalding, L. M. Holland, an J. R. Prine, "The Effects of Dose Protradion on Hematopoiesis in Primate and Dog," Lite Sci. Space Res. X, 155-164 (1972).

12. J. F. Spalding, L. M. Holland, J. R. Prine, P. M. LaBauve, and J. E. London, "Comparative Effects of Dose Protraction and Residual Injury in Dogs and Monkeys," Radiat. Res. 54, 453-462 (1973).

13. J. F. Spalding, L. M. Holland, 0. S. Johnson, J. R. Prine, J. E. London, and P. M. LaBauve, "Recovery and Residual Injury in Monkeys Exposed to Large Doses of Radiation by Fractionation," Los Alamos Scientific Laboratory report LA-5724-MS (September 1974).

14. J. F. Spalding, L. M. Holland, 0. S. Johnson, and J. R. Prine, "Recovery Rate and Residual Injury in Monkeys Exposed to Large Doses of Radiation by Fractionation," Radiat. Res. 62, 70-78 (1975).

15. H. A. Blair, "A Formulation of the Injury, Life Span, Dose Relations for Ionizing Radiations. I Application to the Mouse," University of Rochester report UR-206 (1952).

16. H. A. Blair, "The Constancy of Repair Rate and of Irreparability during Protracted Exposure to Ionizing Radiation, "University of Rochester report UR-621 (1963).

17. National Committee on Radiation Protection and Heasurements, "Exposure to Radiation in an Emergency," L. S. Taylor, Ed. (National Bureau of Standards, Washington, D. C., October 27, 1961), report 29.

18. J. F. Spalding, O. S. Johnson, and G. L. Tiet.jen, "An Investigation of the TwoComponent Radiation Injury Concept Using Equivalent Residual Dose Factors," Los Alamos Scientific Laboratory report LA-5813-MS (January 1975)

19. J. F. Spalding, N. J. Basmann, R. F. Archuleta, and 0 . S. Johnson, "Comparative Effects of Dose Protraction by Fractionation and Ly Continuous Exposure," Radiat. Res. 51, 608614 (1972).

20. R. G. Martinez, G. H. Cassab, G. G. Ganem, E. K. Guttman, M. L. Lieberman, F. L. B. Vater, M. M. Linares, and H. M. Rodriguez, "Observations on the Accidental Exposure of a Family to a Source of Cobalt-60," Revista Med. 3, Supp 1. 1, 14-68 (1964).

21. J. F. Spalding, V. G. Strang, and F. C. V. Worman, "Effect of Graded Acute Exposures of Gamma Rays or Fission Neutrons on Survival in Subsequent Protracted Gamma-Ray Exposures," Radiat. Res. 13, 415-423 (1960). 
22. J. F. Spalding, T, $\Gamma$. Trujillo, and $w . l$. LeStcurgeen, "Dependence of Rate of Recoviry Crom Acute Gamma-Ray Exposure on Size of the Conditionng Dese," Radiat. Kes. 15, 378-389 (1961).
23. J. F. Spalditg, R. F. Archuleta, J. E. London, ard J. R. Prine, "Delayed Radjation Injury of Gut-Exposed and Gut-Shielded Mice. I, The Decremeth in Resistance to Continuous CammaRay Stress," Los Alamos Scientific Laboratory report LA-6717-MS (February 1977). 